\title{
Rapid assessment of fertilizers manufacturing methods by means of a novel waveguide vector spectrometer
}

\author{
Eleonora Iaccheri, ${ }^{1}$ Annachiara Berardinelli, ${ }^{2}$ Claudio Ciavatta, ${ }^{1,3}$ Luigi Ragni ${ }^{1,3}$ \\ ${ }^{1}$ Interdepartmental Centre for Agri-Food Industrial Research, Alma Mater Studiorum - University of Bologna, Cesena \\ (FC); ${ }^{2}$ Department of Industrial Engineering, University of Trento, and Centre Agriculture Food Environment, \\ University of Trento; ${ }^{3}$ Department of Agricultural and Food Science, Alma Mater Studiorum - University of Bologna, \\ Cesena (FC), Italy
}

\begin{abstract}
This study aims to test the suitability of a waveguide spectrometer, as a rapid and cheap tool to discriminate between different fertilizers according to two different manufacturing methods, such as granulation and blending. The tested instrument is a waveguide vector spectrometer, patented in 2016, that operates in the range 1.6-2.7 GHz, giving both spectral phase and gain measurements. Granulated and blended fertilizers were dehydrated and pulverized to avoid possible interferences due to the water content and the geometry of the sample. The spectral data were analysed by multivariate statistical analysis [principal component analysis (PCA) and partial least squares-discriminant analysis (PLS-DA)] in order to obtain a discrimination tool considering the whole hidden spectral information. PC1 (95\% of the explained variance) and PC2 (4\% of the explained variance) are shown to explain most of the spectral variability. A tendency to group samples according to the different production methods can be seen, even if the discrimination is influenced by the different chemical compositions of fertilizers. However, PLS-DA models correctly classified $100 \%$ of the samples into granulated and blended classes using spectra obtained by waveguide spectroscopy. Despite being preliminary, the tests carried out on a small number of samples show how the technique coupled with PLS-DA models could be able to discriminate between the analysed fertilizers by means of their spectral signature and according to the manufacturing
\end{abstract}

Correspondence: Eleonora Iaccheri, Interdepartmental Centre for AgriFood Industrial Research, Alma Mater Studiorum, University of Bologna, via Quinto Bucci 336, 47521 Cesena (FC), Italy.

Tel.: +39.0547.338151

E-mail: eleonora.iaccheri4@unibo.it

Key words: Chemometrics; classification; physical properties; rapid electrical technique.

Conflict of interests: the authors declare no potential conflict of interests.

Received for publication: 18 June 2020.

Accepted for publication: 7 September 2020.

CC Copyright: the Author(s), 2020

Licensee PAGEPress, Italy

Journal of Agricultural Engineering 2020; LI:1093

doi:10.4081/jae.2020.1093

This article is distributed under the terms of the Creative Commons Attribution Noncommercial License (by-nc 4.0) which permits any noncommercial use, distribution, and reproduction in any medium, provided the original author(s) and source are credited. method, if the chemical composition is kept constant. Further tests are necessary to validate the model, also considering the possibility of grouping fertilizers on the basis of their similar composition.

\section{Introduction}

For many years, microwave measurements and dielectric spectroscopy have been recognized as non-destructive techniques for the assessment of chemical and process parameters of agricultural products (Nelson, 1991). The interaction of the electromagnetic wave gives a unique response by tracing the matrix in all its complexity, as a function of stored and lost energy. Dielectric properties are affected by the composition of samples and temperature (Dalacort and Stevan, 2018). Within the microwave frequency the main contribution to the loss spectra comes from ion conductivity and dipole polarization (Castro-Giráldez et al., 2010). Fertilizers include a lot of components that contribute to the dielectric spectra as a function of their chemical composition and molecular polarization.

The use of fertilizers increases significantly the quantity and the quality of vegetable foods (Wu and Liu, 2008). These compounds can be at several physical states. Solid and liquid forms are the most sold (Wu and Liu, 2008; Reg. (EU) 2019/1009). In order to produce solid fertilizers in the most usable form, each of the different compounds (e.g. urea, potassium chloride, ammonium phosphate, triple superphosphate, or other inorganic or organic matrices) are simply mixed or mixed and subsequently granulated (Wu and Liu, 2008).

The granulation method consists in putting the solid materials (either as powders or grains) into inclined axis rotating tilted drum. As the drum rotates, the fragments of wet solid fertilizer take on small spherical shapes, while a wetting solution of acidic water (i.e. highly diluted solution of sulfuric acid, $0.05 \mathrm{M}$ ) is sprayed. The semi-finished product is then passed through a sieve that adequately separates oversize particles. Finally, the particles are dried to complete the granulation process (Wu and Liu, 2008). A fertilizer manufactured (co-formulated) by wet mixing several components implies a homogeneous distribution of the nutrients on the soil surface. As a consequence, granules or pellets can reach the soil surface, according to the characteristics of the centrifugal fertilizer spreader. In the other production method, different compounds, already in the form of particles, are blended, in appropriate proportions, by using a large mixing drum that rotates to obtain the best mixture homogeneity. After mixing, the fertilizer is unloaded onto a conveyor belt, which transports it to the bagging machine. A fertilizer manufactured by dry mixing several separated components involves an uneven distribution of the nutrients on the soil surface. The identification of the production process is important to detect any potential frauds by comparing the same fertilizer formulation in term of nutrient contents and different sales price due to the different costs of the raw materials and production. Considering that agronomic results are better with 
granulated fertilizers obtained by powder wet mixing, it is useful to discriminate between products obtained with different manufacturing processes (simple blend $v s$ wet mixing powders), particularly in case of solid organo-mineral fertilizers (Legislative Decree 75/2010; Reg. (EU) 2019/1009).

Several studies have been conducted to investigate the interaction between electromagnetic fields and product by using waveguide systems, both on non-food (Nelson, 1991) and food materials. As example, water content in corn flour, fat content of milks, carbohydrates in fruit juices and alcohol content in wines and liquors were assessed by (Ragni et al., 2017). Freshness parameters of shell eggs (Ragni et al., 2010), soluble solids content ( ${ }^{\circ}$ Brix) and MagnessTaylor flesh firmness prediction of 'Hayward' kiwifruits (Ragni et al., 2013), different rind percentage of Parmigiano-Reggiano cheese and three competitors' (Cevoli et al., 2015) were also determined by means of electrical field interaction. Furthermore, physical parameter as water availability, expressed in terms of water activity $\left(\mathrm{a}_{\mathrm{w}}\right)$ and the glass transition temperature in green and roasted coffee (Iaccheri et al., 2015, 2019) were investigated. For rapid monitoring of regular bulk distribution, formulation and moisture content of fertilizers, a device based on the LMC555 oscillator integrate circuit was developed by using a mobile helical capacitive sensor, designed according to the dielectric properties of water-soluble fertilizers. An optical sensor was adapted to count the axis rotations per minute and to adjust the axis rotation to simulate the same distribution speed in the field (Dalacort and Stevan, 2018). The dielectric constant $\left(\varepsilon^{\prime}\right)$ and the dielectric loss $\left(\varepsilon^{\prime \prime}\right)$ have been measured at 8 and $10 \mathrm{GHz}$, at room temperature on black soil with the addition of chemical fertilizers. The dielectric constant and the dielectric loss of the soil increase as a function of urea and potassium carbonate quantitative raise. The variation is higher for urea than for potassium carbonate (Navarkhele et al., 2015). The fertilizers produced with the abovementioned methods are indistinguishable at the end of the production process. However, the classification of fertilizers has an economic and technological relevance. In particular, granulated fertilizers are more expensive than blended ones. Moreover, fertilizers differ also for their agronomical characteristics, since granulated fertilizers can be homogeneously spread in the soil, while the distribution of blended fertilizers might result in an aggregation of particles and in the end nutrients may not be evenly distributed in the soil (Dalacort and Stevan, 2018). A rapid technique to identify which production methods was used to make fertilizers + could be very useful. The aim of this work is to investigate the feasibility of a tech- nique based on waveguide vector spectrometer (WVS) to discriminate between the different methods used to produce fertilizers with different chemical compositions available on the marked.

\section{Materials and methods}

\section{Waveguide vector spectrometer}

A WVS that operates in the low region of the microwave spectrum (1.6-2.7 GHz) was recently designed and assembled at the University of Bologna, Italy (Italian patent No. 1421744, 2016, International application: WO2015/107455A1, 2015). The device is a portable, small size, light-weight, powerful and inexpensive spectroscopic instrument. It has already been introduced and tested as rapid tool for the assessment of the main compositional parameters of agri-food products (Ragni et al., 2017; Teslić et al., 2017). The WVS is composed of a rectangular guide in which the sample is located between two antennas, i.e. the transmitting antenna and receiving antenna. The waveguide internal dimensions are $96 \times 46$ $\mathrm{mm}$, with a cut-off frequency of $1.56 \mathrm{GHz}$. A voltage oscillator (Mini-Circuits, ZX95-2800+, Brooklyn, NY, USA) powers the transmitting antenna. Transmitted and received signals are sent to a gain-phase comparator (Analog Devices, AD8302, Norwood, MA, USA). Its voltage outputs are amplified and connected to an USB microcontroller with ADC function (Microchip, PIC18F2550, Chandler, AZ, USA). A DAC (Microchip, MCP4822, Chandler, AZ, USA) connected to the MIC through a voltage ramp amplifier drives the VCO. The power is very low $(3.5$ $\mathrm{dBm})$, so the temperature effect on the sample under test is negligible. The core of the system is the AD8302. Its main features are summarized as follows: frequency range from LF to $2.7 \mathrm{GHz}$; input range from - $60 \mathrm{dBm}$ to $0 \mathrm{dBm}$ in a $50 \mathrm{Ohm}$ system; gain measurement scaling $=30 \mathrm{mV} / \mathrm{dB}$; phase measurement scaling = $10 \mathrm{mV} /$ Degree. The prototype has the following characteristics: number of acquired points $=3132$ (frequency resolution $=0.35$ $\mathrm{MHz}$ in the range from 1.6 to $2.7 \mathrm{GHz}$ ); acquisition time $=36 \mathrm{~s}$; resolution: gain $=0.03$; phase $=0.18$ degree; $\mathrm{A} / \mathrm{D}$ conversion: 10 bits. A Java based software with acquisition, saving and graphical functions was written and used for communication between the WVS and the PC. A concise schematic layout of the system is reported in Figure 1.

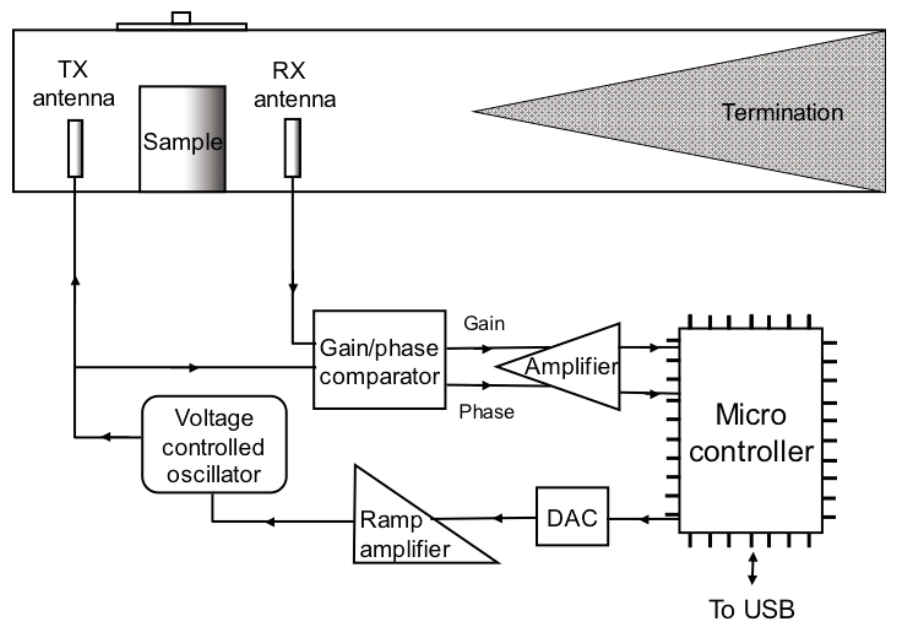

Figure 1. Layout of the waveguide vector spectrometer. TX, transmitting; RX; receiving; DAC, digital analogue converter. 
In order to acquire gain and phase spectra of the fertilizer samples, an experimental set up based on the WVS was used. A customized Java program was used to acquire and transfer the data of the gain and phase spectra. The measurements were carried out in the whole spectrometer frequency range from 1.6 to $2.7 \mathrm{GHz}$ frequency. Each fertilizer was placed in an empty glass container of known volume (19.79 ml, height $36.85 \mathrm{~mm}$ ), until it was full. The repeatability of the volume was tested in a previous work (Ragni et al., 2017) to avoid possible influence on spectral data. The measurements of both air (acquired with empty sample holder) and fertilizer samples were made in about $36 \mathrm{~s}$ per sample, at constant room temperature $23^{\circ} \mathrm{C}( \pm 1)$ and repeated at least in triplicate. The spectrum acquired with the empty sample holder was subtracted from each spectrum to eliminate any possible environmental influence.

\section{Fertilizers}

Fertilizer samples were kindly supplied by $\operatorname{SCAM}{ }^{\circledR}$ Spa (Modena, Italy). To get acquainted with the status of the fertilizers belonging from the two different production processes, each fertilizer having a different composition was produced according to both the granulation method and the blending method. The resulting fertilizers are indicated below as granulated and blended. The chemical composition of the five fertilizers analysed (Italian Official Analytical Methods for Fertilizers, Ministerial Decree, March 24, 1986 and subsequent modifications and additions) for each manufacturing method are reported in Table 1.

In hygroscopic materials, such as fertilizers, the amount of water is the main factor affecting the dielectric properties. Therefore, in order to eliminate any possible influence of the water content and geometry of the material on gain and phase measurements, fertilizers were dried $\left(105 \pm 1^{\circ} \mathrm{C}\right.$, until steady weight), pulverized (commercial cutter, Moulinex ${ }^{\circledR}$ Italia, grinder MC300132, Groupe SEB, France) and subsequently sieved at steady particle size (about $1 \mathrm{~mm}$ ). Measurements were conducted on 10 samples in triplicate (30 spectra acquired).

\section{Data analysis}

For both gain and phase parameters, spectral information was processed by multivariate data analysis. Two well-known techniques were tested: principal component analysis (PCA) and partial least square - discriminant analysis (PLS-DA) (The Unscrambler ver.9.7, CAMO, Oslo, Norway) (Camo Software AS, 2005; Rosipal, 2010).

PCA was applied to all data points (3132 spectral data points for each fertilizer for both gain and phase) involving all samples with different chemical compositions and production methods. The optimal number of : principal component (PC) was selected by analysing as many PCs as the number of variables in the data table.

PLS-DA was the method used to discriminate between the two production processes. PLS-DA was carried out by creating two initial binary classes made with samples from either the granulated (class 0 ) and blended (class 1) methods (each class contained the five-fertilizer spectrum composed by 3132 spectral data points). The predefined classes were used as a-priori information $(\mathrm{Y})$ to build classification models able to predict the different production processes based on the spectral data collected with the waveguide technique $(\mathrm{X})$. The test set validation was used for model validation ( $20 \%$ of samples, randomly selected).

Table 1. Composition of the different fertilizers.

\begin{tabular}{|c|c|c|c|c|c|c|}
\hline & & Azoto N30 & Nutrigan Top & Agrofert & Super Robur & Super Alba \\
\hline Parameters declared (\%) & & A & B & C & D & $\mathbf{E}$ \\
\hline Nitrogen $(\mathrm{N})$ & $\begin{array}{c}\text { Organic } \\
\text { Ammonium } \\
\text { Urea }\end{array}$ & $\begin{array}{c}1.0 \\
6.0 \\
23.0\end{array}$ & $\begin{array}{l}1.0 \\
7.0 \\
2.0\end{array}$ & $\begin{array}{l}1.0 \\
6.2 \\
2.8\end{array}$ & $\begin{array}{c}1.0 \\
11.0 \\
2.5\end{array}$ & $\begin{array}{l}1.0 \\
7.0 \\
8.0\end{array}$ \\
\hline Sulfuric trioxide $\left(\mathrm{SO}_{3}\right)$ & & 15.0 & 7.5 & 14.0 & 26.0 & 10.0 \\
\hline Zinc (Zn) & & 0.01 & 0.01 & 0.01 & 0.5 & 0.01 \\
\hline Total organic carbon (C) & & 7.5 & 7.5 & 7.5 & 7.5 & 7.5 \\
\hline Humic organic carbon $(\mathrm{C})^{*}$ & & 2.7 & 3.2 & 3.0 & 2.7 & 3.0 \\
\hline Potassium oxide $\left(\mathrm{K}_{2} \mathrm{O}\right)$ & N & & & 15.0 & 5.0 & 18.0 \\
\hline Magnesium oxide (MgO) & & & & 3.0 & & \\
\hline Boron (B) & & & & 0.05 & & \\
\hline Iron $(\mathrm{Fe})$ & & & & 0.5 & 0.5 & \\
\hline Phosphorous pentoxide $\left(\mathrm{P}_{2} \mathrm{O}_{5}\right)$ & & & 20.0 & 5.0 & 5.0 & 9.0 \\
\hline Calcium oxide $(\mathrm{CaO})$ & & & 8.0 & & & \\
\hline Humification rate $(\mathrm{HR})^{* *}$ & & 36.0 & 40.0 & 40.0 & 36.0 & 40.0 \\
\hline
\end{tabular}

*Humic organic carbon (C) = humic acid (HA) plus fulvic acid (FA) carbon; **Humification rate, HR = (Humic organic C)/ (Total organic C) $\times 100$.

Table 2. Physical parameters of granulated and blended fertilizers (water content measured by the oven method, $105 \pm 1^{\circ} \mathrm{C}$ until constant weight; density obtained by weighting a constant volume of the commercial product).

\begin{tabular}{|c|c|c|c|c|c|c|}
\hline Parameters & & $\mathbf{A}$ & B & C & D & $\mathbf{E}$ \\
\hline Water content (\%) & $\begin{array}{c}\text { Granulated } \\
\text { Blended }\end{array}$ & $\begin{array}{l}2.23( \pm 0.15) \\
8.30( \pm 0.47)\end{array}$ & $\begin{array}{c}3.59( \pm 0.15) \\
15.25( \pm 0.64)\end{array}$ & $\begin{array}{c}3.14( \pm 0.35) \\
12.27( \pm 0.51)\end{array}$ & $\begin{array}{c}4.20( \pm 0.40) \\
12.61( \pm 0.90)\end{array}$ & $\begin{array}{c}5.04( \pm 0.38) \\
11.75( \pm 0.42)\end{array}$ \\
\hline Density $\left(\mathrm{kg} / \mathrm{m}^{3}\right)$ & $\begin{array}{c}\text { Granulated } \\
\text { Blended }\end{array}$ & $\begin{array}{l}705( \pm 9) \\
684( \pm 4)\end{array}$ & $\begin{array}{l}878( \pm 3) \\
843( \pm 5)\end{array}$ & $\begin{array}{l}882( \pm 13) \\
778( \pm 20)\end{array}$ & $\begin{array}{l}813( \pm 9) \\
784( \pm 4)\end{array}$ & $\begin{array}{c}886( \pm 20) \\
815( \pm 9)\end{array}$ \\
\hline
\end{tabular}

Note: density was measured before pulverization. Density after pulverization was not different among the selected fertilizers. 


\section{Results and discussion}

The determination of water content and density of granulated and blended fertilizers are reported in Table 2.

As expected, different manufacturing methods produced a different moisture and density of the products. The differences in terms of water content and density were standardized by sample dehydration and pulverization procedures necessary to avoid a possible influence of these factors on the response of the wave interaction with the material. The recorded spectra were acquired on powder dehydrated samples. Therefore, every component represents an important spectral datapoint. However, the discrepancy in terms of composition was not the aim of this study. It should also be noted that many different components can overlap in different products. The difference in the two production methods was investigated in depth by grouping spectra, then the statistical analysis was used to highlight any difference among the selected fertilizers.

Averaged gain $(\mathrm{dB})$ and phase $\left(^{\circ}\right)$ signals grouped by manufacturing method, as granulated and blended, in the selected frequency range 1.6-2.7 GHz are shown in Figures 2 and 3, respectively.

Overall, the spectra of each fertilizer obtained with the two production methods are distinguishable. The most relevant differences can be seen in the gain spectra, as shown by Figure 4.

In this way, it can be possible to observe the discriminative potential of the technique by maintaining the chemical composition constant. In particular, granulation appeared to be the method with greater variability. As far as this method is concerned, it is
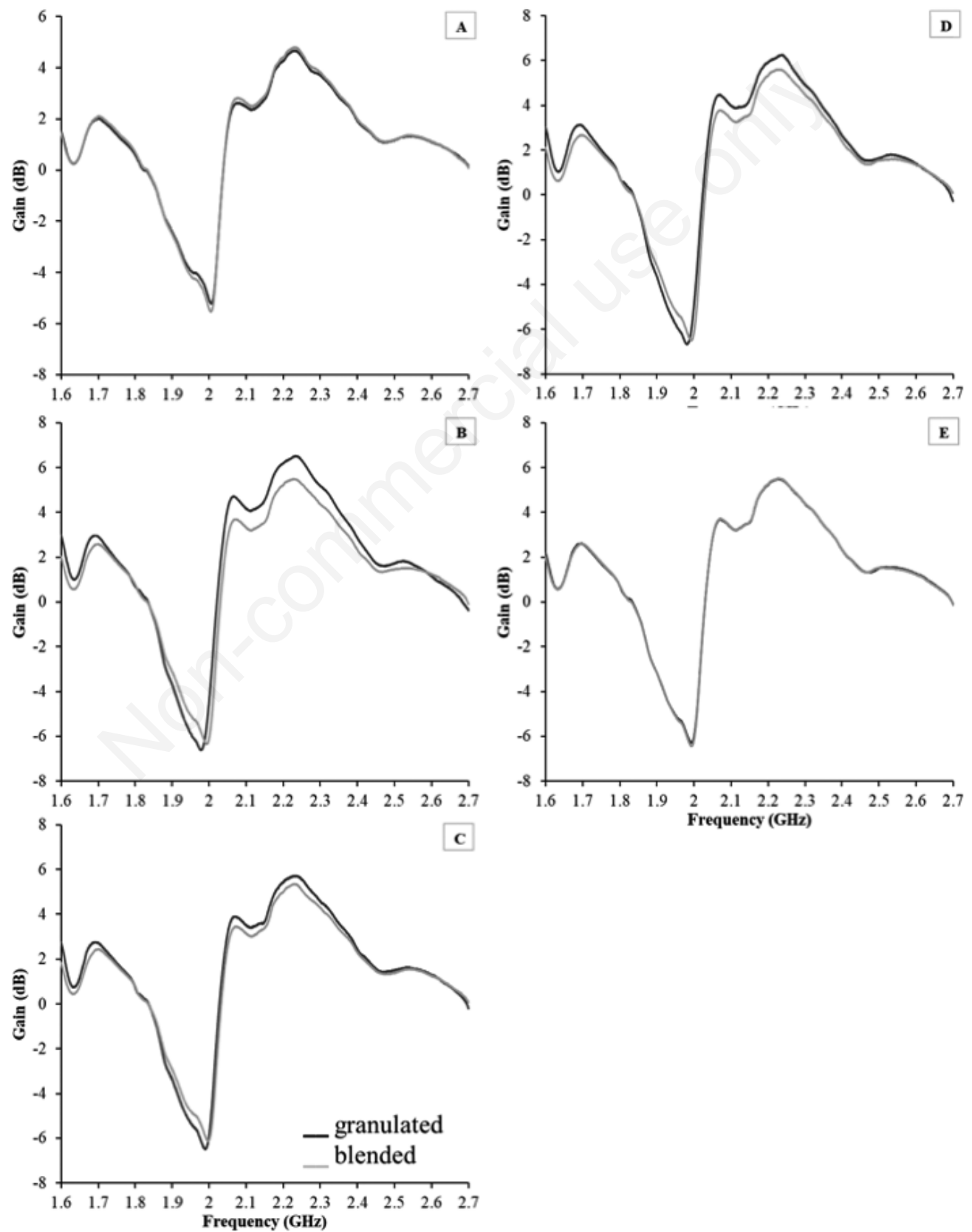

Figure 2. Average gain signal for the five fertilizers analysed (A, B, C, D and E: see Table 1). 

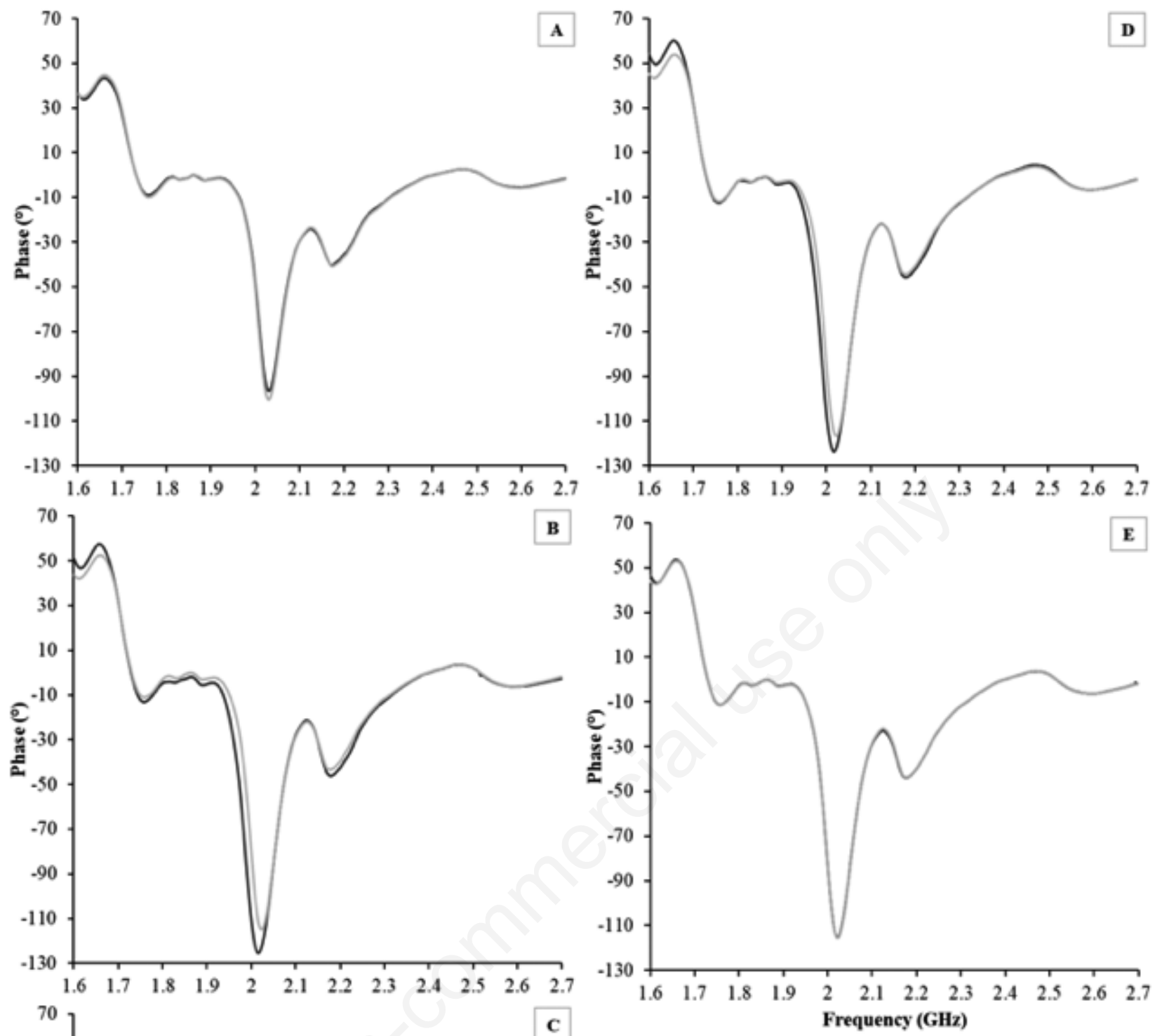

$\mathbf{E}$
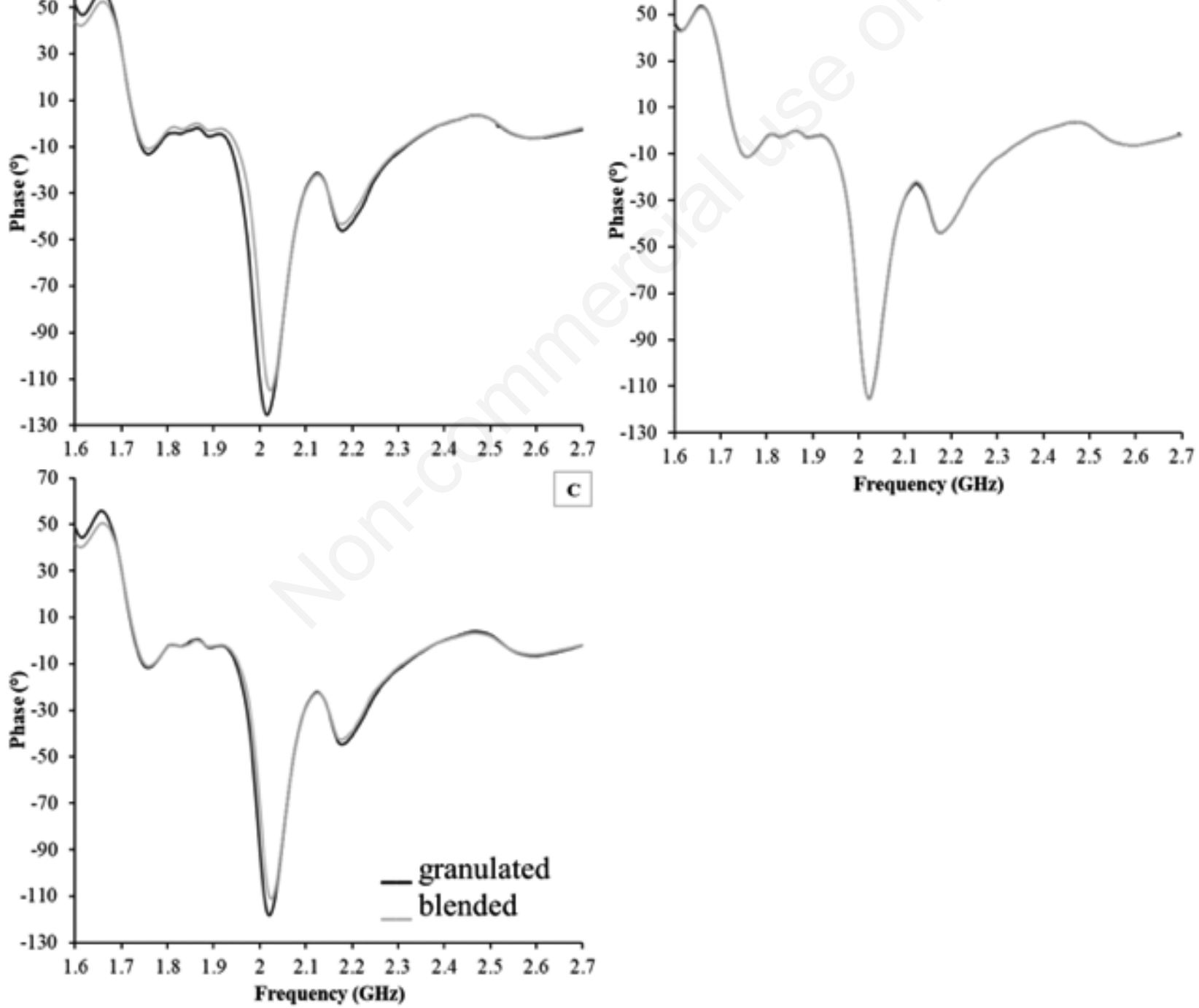

Figure 3. Average phase signal for granulated and blended fertilizers. 
important to remember that ingredients come into contact immediately into contact and are processed together. Therefore, the greatest differences may be attributable to the interaction between the various components. The interactions in the blending method are practically absent and fewer variations are seen in the spectrum.

The constant chemical composition is one of the main innovative aspects of this study. Previously, several works were conducted to estimate qualitative attributes of agricultural products through a spectroscopic analysis of the waveforms. The differences in chemical composition were used to interpret the electromagnetic field perturbation. A preliminary analysis of all signals was conducted by using the unsupervised PCA analysis. The results of the principal component analysis are reported in Figure 5 , for gain and phase spectra, respectively.
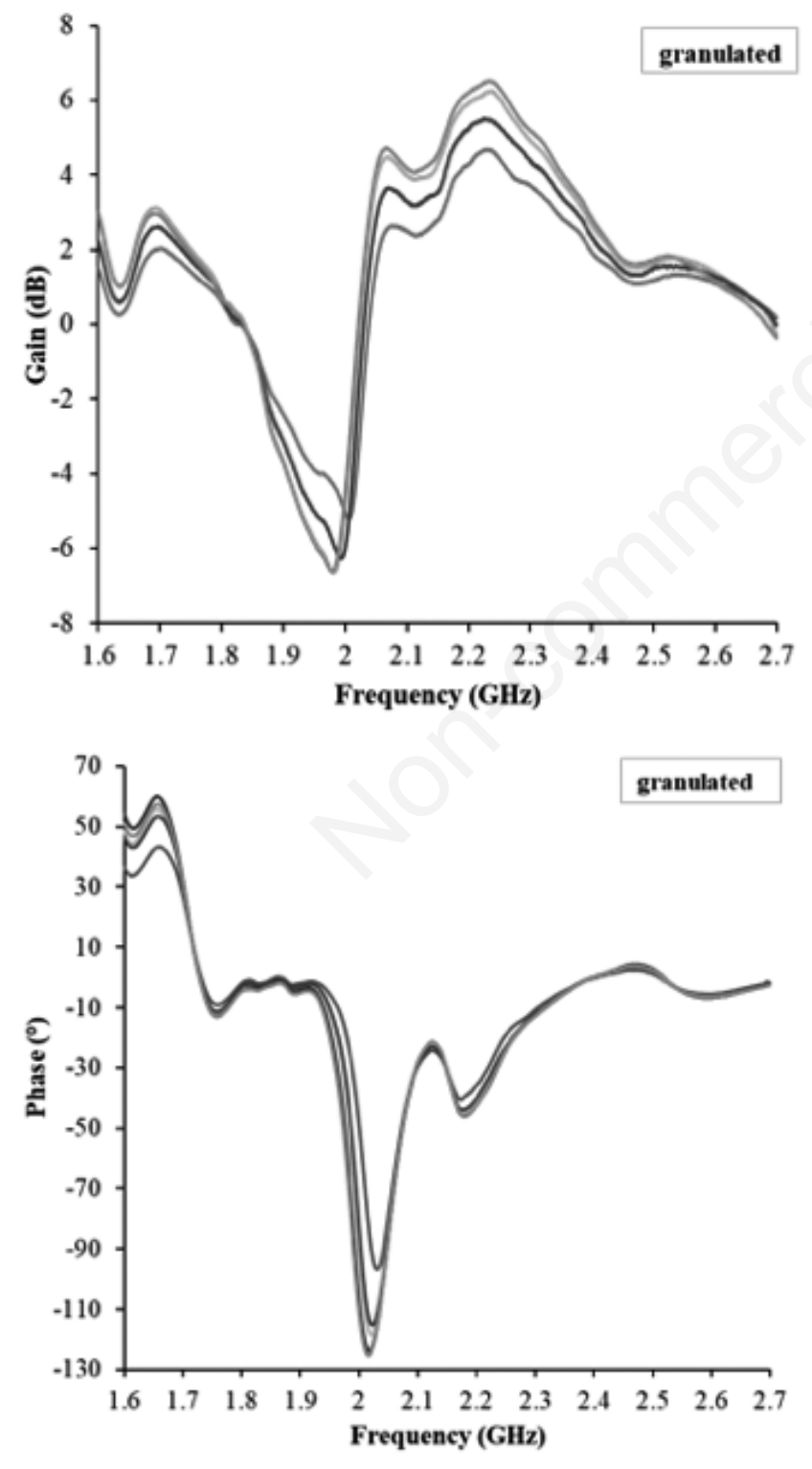

As to the gain signals, the two principal components, PC1 (95\% of the explained variance) and PC2 (4\% of the explained variance), can explain most of the spectral variability. Therefore, from the score plot it can be possible to observe a tendency to discriminate according to the production method. However, there is not a perfect separation, as the spectra are influenced by the different chemical compositions. For instance, sample A has the most different composition, therefore it is allocated in the left part of the score plot, thus also separated for composition.

The phase spectra are characterized by the same behaviour, also in terms of principal component descriptors. More samples should be analysed to improve the sample data set and build a model grouping by classes characterized by similar compositions. Grouping fertilizers according to their chemical formulation could
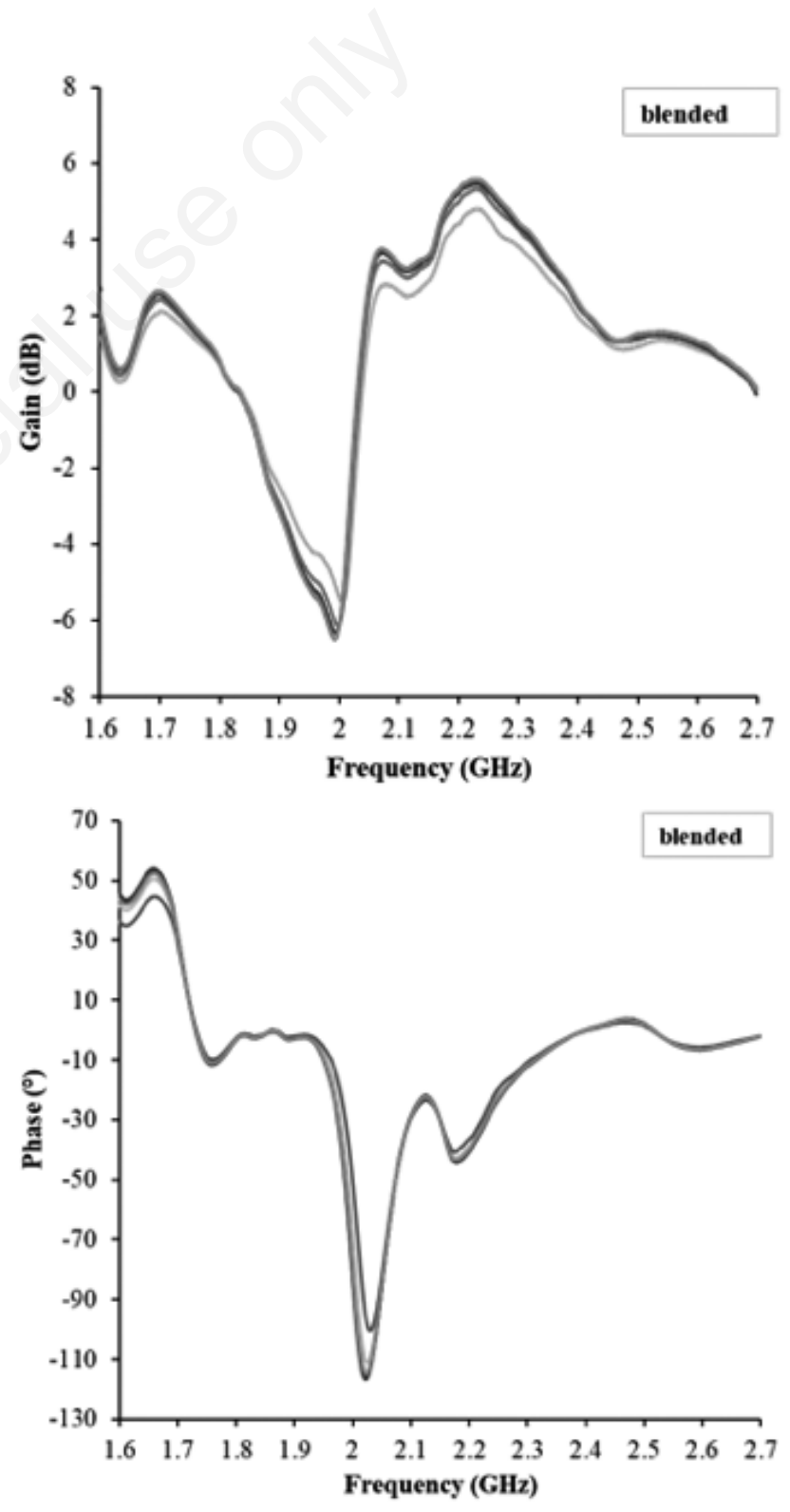

Figure 4. Average gain and phase spectra related to the granulated and blended production processes of all fertilizers considered. 
compensate for the sensitivity of this technique to the chemical composition, also allowing the model to separate clearly the two production processes. Therefore, a new PCA was performed and reported in Figure 6. As expected, the PCA analysis can separate the different fertilizers according to their chemical composition. Unfortunately, the PCA did not show a significant discrimination potential according to the production methods. However, the PCA showed a tendency to group samples according to the different production methods, even if the result is influenced by their chemical composition.
The PLS-DA model was implemented to obtain a more effective classification. Usually, the PLS-DA technique includes a confusion matrix which is useful to calculate the accuracy, the specificity, and the sensitivity of the classification model (Beghi et al., 2017). The PLS-DA was then applied to test the possibility to classify samples according to their production method. Figure 7 showed that the PLS-DA is a powerful discrimination tool and the two classes are well visible with either granulated or blended samples. The PLS-DA supervised method classified correctly $100 \%$ of samples and proved to be a better classifier than the PCA method.
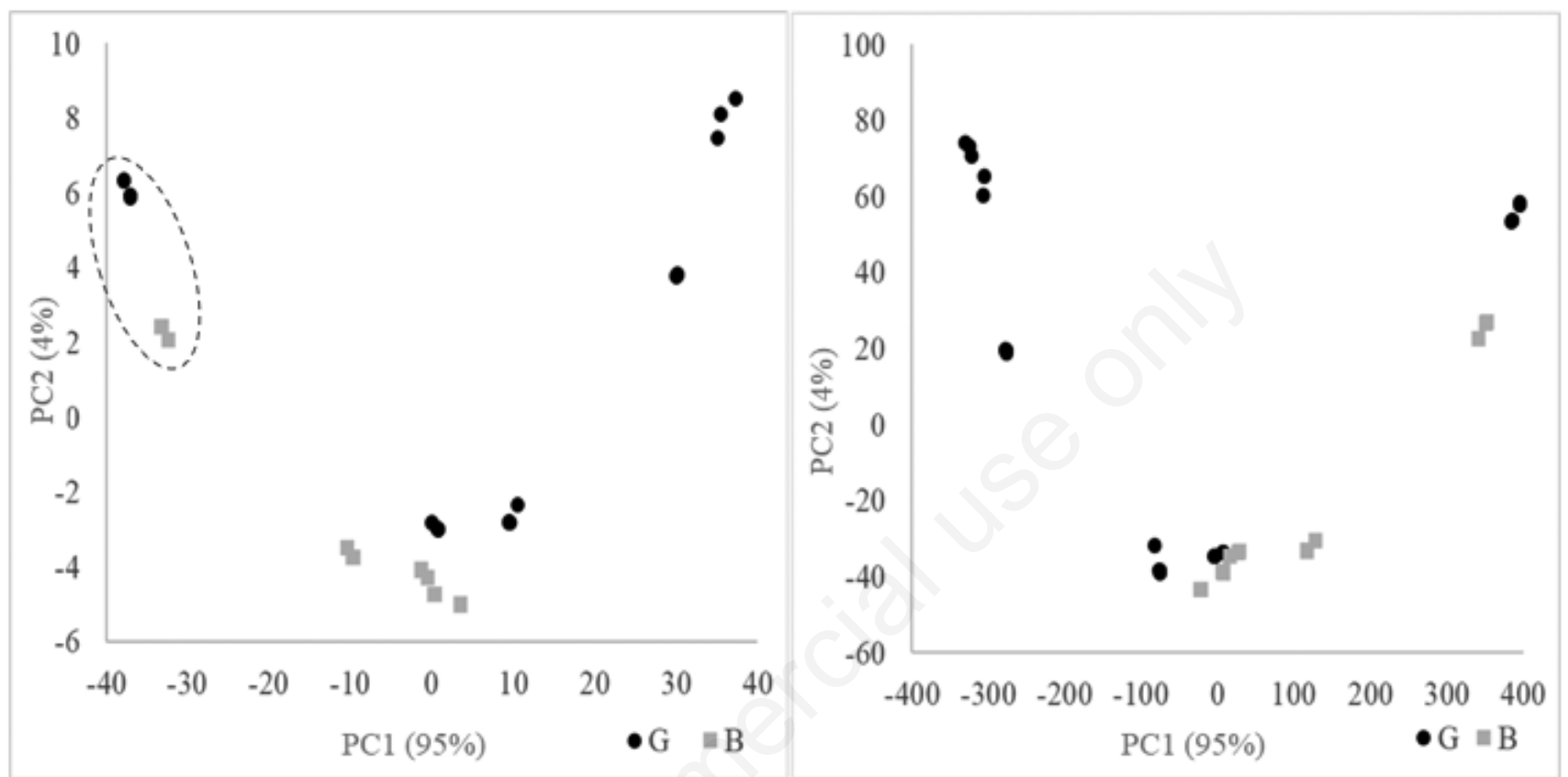

Figure 5. Principal component analysis (PCA) score plot for gain (left) and phase (right) signals. The dashed circle contains fertilizer A. G, granulated; B, blended.

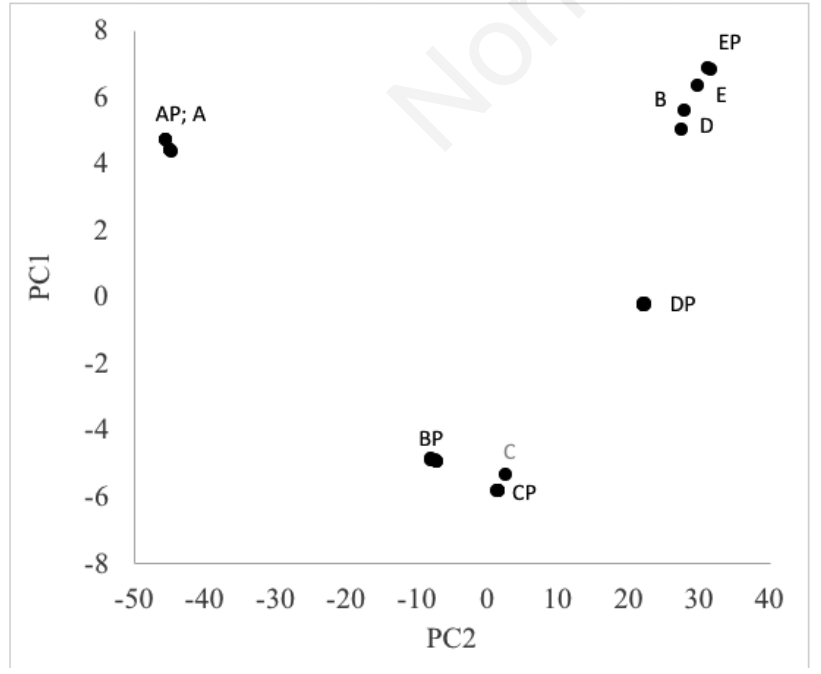

Figure 6. Principal component analysis (PCA) score plot grouping according to the chemical composition (letter $P$ indicates the blended production method); (AP, A; BP, B; CP, C; DP, D; EP, E). granulated; B, blended.

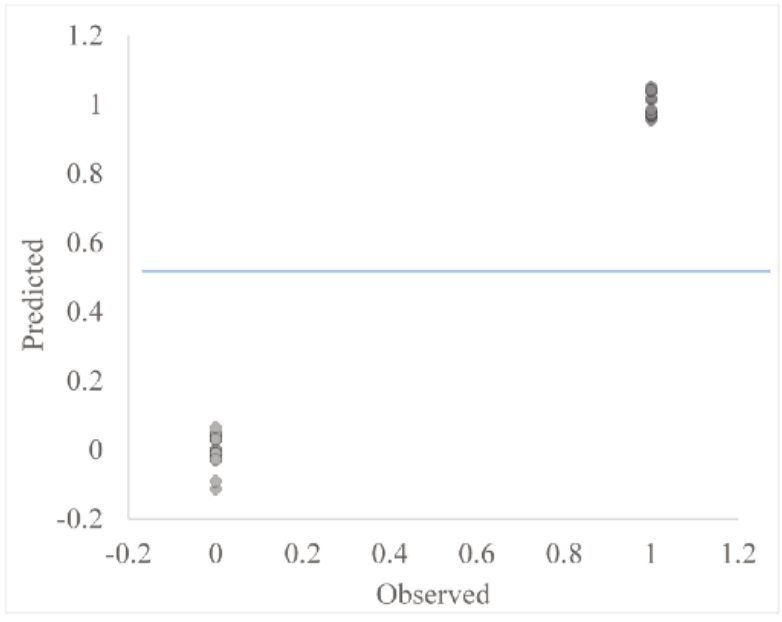

Figure 7. Partial least squares-discriminant analysis results showing the distinction between the two classes. 
It should be emphasized that the two-input classes strategy yielded better results than the one-input class strategy.

Although all the samples were correctly classified, in the future a validation method should be applied. However, it can be observed that all the $\mathrm{Y}$ values were close to 1 or 0 and no samples were found around 0.5 . This is important to reduce the misclassification for future predictions.

\section{Conclusions}

The tests carried out showed how this technique combined with statistical multivariate analyses could be able to discriminate between the analysed fertilizers on the basis of their production process by maintaining the composition constant. The waveguide technique confirmed its the ability to assess a non-destructive signature of the matrix, also considering the rapidity and affordability of the proposed instrument. Therefore, the PCA analysis in terms of both gain and phase showed a not a clear ability to separate fertilizers into two distinct groups characterized by different manufacturing methods. However, as to the chemical composition assessment, the PCA analysis achieved good results. The PLS-DA was proposed to overcome discrimination problems and proved able to distinguish very well between the two production processes.

The waveguide vector spectrometer is a portable instrument and could be directly used for industry audit as non-destructive analysis to avoid frauds and control the products. The fertilizer classification can also have some agronomical importance in terms of spread potential and availability of nutrients in soils.

Further insights and physical and chemical investigations could explain the reasons for the different spectral response to the microwave field related to the different types of fertilizer manufacturing processes.

\section{References}

Beghi R., Giovenzana V., Brancadoro L., Guidetti R. 2017. Rapid evaluation of grape phytosanitary status directly at the check point station entering the winery by using visible/near infrared spectroscopy. J. Food Engine. 204:46-54.

Castro-Giráldeza M., Botella P., Toldrà F., Fito P. 2010. Low-frequency dielectric spectrum to determine pork meat quality. Innov. Food. Sci. Emerg. Technol. 11:376-86.

Cevoli C., Ragni L., Iaccheri E., Gori A., Caboni M.F., Guarnieri A., Berardinelli A. 2015. Estimation of the main compositional features of grated Parmigiano Reggiano cheese by a simple capacitive technique. J. Food Eng. 149:181-7.
Dalacort R., Stevan S.L. 2018. Mobile helical capacitive sensor for the dynamic identification of obstructions in the distribution of solid mineral fertilizers. Sensors (Basel, Switzerland) 18:3991.

Iaccheri E., Laghi L., Cevoli C., Berardinelli A., Ragni L., Romani S., Rocculi, P. 2015. Different analytical approaches for the study of water features in green and roasted coffee beans. J. Food Eng. 146:28-35.

Iaccheri E., Ragni L., Cevoli C., Romani S., Dalla Rosa M., Rocculi P. 2019. Glass transition of green and roasted coffee investigated by calorimetric and dielectric techniques. Food Chem. 301:125187.

Legislative Decree April 29, 2010 n. 75. Reorganization and revision of the rules on fertilizers, in accordance with article 13 of the law July 7, 2009, n. 88. Italian Official Gazette n. 126, May 26, 2010.

Navarkhele V.V., Kapre A.K., Shaikh A.A. 2015. Dielectric properties of black soil with chemical fertilizers at X-band. Indian J. Radio Space Phys. 44:102-5.

Nelson O.S. 1991. Dielectric properties of agricultural products. measurements and applications. IEEE Trans. Electr. Insulat. 26:845-69.

Ragni L., Berardinelli A., Cevoli C., Filippi M., Iaccheri E., Romani A. 2017. Assessment of food compositional parameters by means of a waveguide vector spectrometer. J. Food Eng. 205:25-33.

Ragni L., Cevoli C., Berardinelli A. 2010. A waveguide technique for non-destructive determination of egg quality parameters. J. Food Eng. 100:343-8.

Ragni L., Iaccheri E., Cevoli C., Berardinelli A., Bendini A., Toschi T.G. 2013. A capacitive technique to assess water content in extra virgin olive oils. J. Food Eng. 116:246-52.

Regulation (EU) 2019/1009 of the European Parliament and of the Council of 5 June 2019 laying down rules on the making available on the market of EU fertilizing products and amending Regulations (EC) No 1069/2009 and (EC) No 1107/2009 and repealing Regulation (EC) No 2003/2003. 25.6.2019 EN OJ, L $170 / 1$.

Rosipal R. 2010. Nonlinear partial least squares. An overview. In: H. Lodhi and Y. Yamanishi (Eds.), Chemoinformatics and advanced machine learning perspectives: complex computational methods and collaborative techniques. IGI Global, Hershey, PA, USA, pp. 169-189.

Teslić N., Berardinelli A., Ragni L., Iaccheri E., Parpinello G.P., Pasini L., Versari A. 2017. Rapid assessment of red wine compositional parameters by means of a new Waveguide Vector Spectrometer. LWT - Food Sci. Technol. 84:433-40.

Wu L., Liu M. 2008. Preparation and properties of chitosan-coated NPK compound fertilizer with controlled-release and waterretention. Carbohyd. Polym. 72:240-7. 